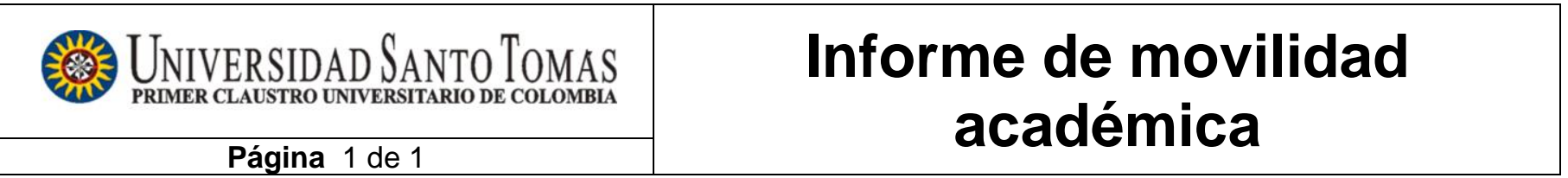

CONSECUTIVO:

FECHA

\section{DATOS GENERALES}

$\begin{array}{ll}\text { NOMBRES Y APELLIDOS: } & \text { FERNANDO CHAVARRO MIRANDA } \\ \text { CORREO ELECTRÓNICO: } & \\ \text { INSTITUCIÓN DESTINO: } & \begin{array}{l}\text { Coloquio Liberty Fund, "Political Economy and Freedom in Ludwig von Mises`s Lost } \\ \text { Papers" }\end{array}\end{array}$

CIUDAD DESTINO:

Buenos Aires

PAÍS

DESTINO:

Argentina

OBJETIVO:

\section{TIPOS DE MOVILIDAD}

1. MOVILIDAD DE LA COMUNIDAD USTA

\begin{tabular}{|c|c|c|}
\hline \multirow[b]{2}{*}{ Curso corto/Entrenamiento } & \multicolumn{2}{|c|}{ DOCENTES/DIRECTIVOS/ADMINISTRATIVOS } \\
\hline & Conferencista/ponente/organizador de un evento & $\mathrm{x}$ \\
\hline Misión institucional & Formación Curso corto/entrenamiento & \\
\hline Ponente u Organizador de evento & Docencia en programa internacional & \\
\hline Auxiliar de investigación/Miembro semillero & Estancia doctoral o postdoctoral & \\
\hline Pasantía investigación/Práctica Académica & Misión/gestión/asesoría externa & \\
\hline \multirow{2}{*}{ Presentación Buenas Prácticas } & Estancia de investigación & \\
\hline & Presentación de Buenas Prácticas USTA & \\
\hline
\end{tabular}

\section{MOVILIDAD EXPERTOS EXTERNOS A LA USTA}

Profesor en pregrado o posgrado

Conferencista/ponente

Cursos cortos /entrenamientos

\section{PLAN DE TRABAJO}

Participe como experto en el evento, denominado Coloquio de Liberty Fund; "Political Economy and Freedom in Ludwig von Mises`s Lost Papers", socialice con los participantes internacionales lo pertinente al proceso investigativo que adelanto en mi área de experticia; igualmente obtuve un gran cumulo de información, lo que me permitirá enriquecer aun más los procesos de investigación en los que estoy inmerso dentro de la Facultad de Administración de Empresas. 


\begin{tabular}{|c|c|}
\hline UNIVERSIDAD SANTOTOMAS & Informe de movilidad \\
\hline
\end{tabular}

\section{APORTE A DOCENCIA, INVESTIGACIÓN O PROYECCIÓN SOCIAL}

Esta participación, permitirá que se pueda nutrir el currículo con las nuevas experiencias obtenidas en este evento, y a la vez se potencialice el proceso investigativo dentro de la Facultad de Administración de Empresas.

Igualmente permitió que en adelante, se puedan replicar los conocimientos adquiridos en la implementación de procesos de estructuración de tanques de pensamiento, que permitan a futuro poder debatir al interior de la Facultad, con nivel de académicos y estructuraciones inmersas en los procesos de investigación.

La participación en el evento, obedece al reconocimiento internacional del Docente como investigador internacional, y permite que los avances de investigación que viene realizando, los pueda presentar como experto en la ciudad de Buenos Aires- Argentina; igualmente permitirá que se pueda nutrir el currículo con las nuevas experiencias obtenidas en este evento, y a la vez se potencialice el proceso investigativo dentro de la Facultad de Administración de Empresas.

\section{ACTIVIDADES DE COOPERACIÓN}

Se adelantaron conversatorios que permitirán a futuro ilustrar y documentar a otros investigadores de la Facultad, así como a los estudiantes de los semilleros y otros más.

En los procesos que adelanta la Facultad de Administración de Empresas, permitió que en adelante, se puedan replicar los conocimientos adquiridos en la implementación de Tanques de Pensamiento, que nutran el debate académico al interior de la Facultad, e irradien estas experiencias a los respectivos grupos de investigación.

se buscaron los contactos iniciales, que permitan en el futuro traer académicos de alto nivel internacional, y poder lograr compartir con ellos, su riqueza intelectual y académica, dentro de la Universidad Santo Tomas, y más específicamente dentro de la Facultad de administración de Empresas.

\begin{tabular}{|c|l|l|l|}
\hline \multicolumn{3}{|c|}{ CONTACTOS } \\
\hline NOMBRE & CORREO ELECTRÓNICO & \multicolumn{1}{|c|}{ INSTITUCIÓN/CARGO } & \multicolumn{1}{c|}{$\begin{array}{c}\text { OBJETIVO DEL } \\
\text { CONTACTO }\end{array}$} \\
\hline Juan Sebastián Landoni & & $\begin{array}{l}\text { Universidad Francisco } \\
\text { Marroquín }\end{array}$ & $\begin{array}{l}\text { Movilidad } \\
\text { Investigadores }\end{array}$ \\
\hline
\end{tabular}

\section{PLAN DE TRANSFERENCIA}

Se adelantaran conversatorios que permitan ilustrar y documentar a otros investigadores de la Facultad, así como a los estudiantes de los semilleros y otros más.

\section{EVIDENCIAS (ANEXOS)}

Se adjuntan al presente documento, certificación del Coloquio .

\section{IDENTIFICACIÓN DE OPORTUNIDADES DE MEJORA}

Los tramites del proceso de movilidad fueron bastante agiles; se recomienda que las movilidades se puedan extender unos dos o tres días, a efecto de poder concretar algunos contactos y definir algunas estrategias, lo anterior para poder obtener un mejor resultado de los procesos de movilidad. 